\title{
MEGAPROYECTOS, ENTRE EL COLONIALISMO INTERNO Y LA COMUNALIDAD. \\ Disputa por el territorio en el Istmo de Tehuantepec
}

\section{Humberto Márquez Covarrubias*}

En Conflictos socioambientales, derechos humanos y movimiento indígena en el Istmo de Tebuantepec, Carlos Lucio (2016) emprende una crítica necesaria a la teoría y práctica del desarrollo desde la perspectiva del pensamiento descolonizador; su referente son los pueblos indígenas de México, en particular dos casos del Istmo de Tehuantepec, Oaxaca: uno de ellos el pueblo mixe que desde mediados del siglo pasado padece los embates del desarrollo regional basado en las cuencas hidrológicas, el otro aborda el proceso de resistencia a un megaproyecto eólico que desencadena la defensa del territorio donde está asentado el modo de vida.

De manera frontal, se analiza el desarrollo a partir de la idea de que en México la relación entre el Estado y los pueblos indígenas se ha tensado y entrado en conflicto por las políticas de desarrollo que en los planos nacional y local reeditan las formas de despojo territorial, con mayor énfasis en el actual modelo neoliberal, para abrir paso a los grandes capitales que quieren rentabilizar el territorio. Con ello vulneran el modo de vida de los pueblos indígenas en la medida en que niegan su cultura y constitución como sujetos sociales y aniquilan sus derechos.

El desarrollo se torna en un dispositivo económico y político de amplio espectro para satisfacer la lógica de la renta de la tierra, que al subsumir la diversidad biocultural se vuelve una renta de la vida, en el sentido de que

* Docente-investigador de la Unidad Académica de Estudios del Desarrollo de la Universidad Autónoma de Zacatecas, México. 
toda la variedad de la biósfera y el metabolismo social entre los pueblos y el ambiente pretende ser engullido por los mercados capitalistas.

Se interpreta entonces que el modelo de desarrollo, sus políticas e instituciones promotoras, más que una teoría económica o un proyecto civilizatorio orientado por el progreso para el conjunto de la sociedad, significa un modo de dominación que debe ser desmontado en clave histórica con la finalidad de entender su devenir y la sujeción de pueblos y clases sociales subalternas, donde se encuentran, en primer lugar, las comunidades indígenas, y en seguida las comunidades campesinas, el resto de clases y sectores subordinados. Para hacerlo, Carlos Lucio recupera un concepto clave, «colonialismo interno», elaborado al alimón por Rodolfo Stavenhagen (1963) y Pablo González Casanova (1963), como una extensión de la perspectiva teórica de la dependencia tendida en el largo plazo, cuya raíz es el proceso de colonización, el dominio de la Corona en la Nueva España. Lo anterior representó la sujeción de los diversos pueblos indígenas que habitaban estas tierras, a quienes no se les atribuía ni siquiera un alma (después se decía que no eran personas de razón, sólo de costumbre) de manera que debían ser evangelizados; a su vez, eran explotados con objeto de saquear las riquezas naturales, en particular los metales preciosos que se extraían con el trabajo esclavo y se transferían a Europa. En ese momento, aquel continente experimentaba su acumulación originaria, que luego desplegaría la Revolución industrial, en consecuencia comenzaría el desarrollo del capitalismo teniendo como trasfondo las sucesivas oleadas de innovación y el saqueo permanente de los territorios indígenas durante la Colonia y la Independencia o poscolonia. El saqueo no se ha detenido, más aún, en la era del capital global se ha multiplicado.

Los procesos de independencia y la formación de los Estados poscoloniales no cancelaron el sometimiento de los pueblos indígenas, sino que prolongaron la dominación bajo la forma del colonialismo interno. 
Esta es una pista clave del libro. El proceso de formación del Estado poscolonial es contradictorio y no deja atrás los mitos de la Colonia que justifican el sometimiento de los pueblos originarios bajo la égida de la espada y la cruz, así como el postrero mito del mestizaje que niega o relega la cultura indígena o la recodifica con una política indigenista con afanes integracionistas. Además, es consecuente con el eurocentrismo de las elites políticas y las nociones de la modernidad capitalista que orientan las políticas de desarrollo, llámese industrialización por sustitución de importaciones o neoliberalismo, visiones donde no tienen cabida los indígenas, pero sí sus territorios.

No obstante, persiste un México profundo (Bonfil, 1990), un espacio antropológico que no puede diluirse en el Estado nación, monocultural y dominante, por tanto excluyente y racista. Un espacio social extenso, como la geografía mexicana, aunque con mayores grados de densidad histórica y segregación social. Es el caso del Istmo de Tehuantepec, una zona que se niega a disolverse en la comunidad imaginaria del Estado nación y que se resiste a ser despojada.

La Revolución mexicana, que pudiera interpretarse como un movimiento burgués con respaldo popular, a lo sumo reivindica al campesinado, mestizo, pero sin hacer un reconocimiento a la raíz indígena y a la raíz negra afrodescendiente. En la etapa posrevolucionaria se procesa un colonialismo interno bajo el mito del mestizaje y la dominación política de un partido-Estado que se prolonga hasta nuestros días, y tiene como correlato una política indigenista que pretende fundir a los pueblos originarios en un Estado-nacional, un proceso de integración cultural que es la negación práctica de la diversidad cultural indígena y el desconocimiento de sus derechos. Esta política fracasará por la emergencia de movimientos indígenas en varios lugares del país que reivindican su cultura y derechos a la vez que se resisten a las varias formas de despojo territorial y explotación. 
El zapatismo pudo sintetizar política y conceptualmente las aspiraciones de los pueblos indígenas y fue más allá al plantear una nueva forma de hacer política (que se puede resumir en la reivindicación de la autonomía y el precepto del «mandar obedeciendo», aunque no se agota en ello). No obstante, no logró cristalizar los Acuerdos de San Andrés ante una clase política indolente, por lo que el movimiento pasó a otras formas de organización, distantes del Estado y los partidos políticos.

En sintonía con esas reivindicaciones, en otros momentos, diversas comunidades indígenas se han organizado y movilizado para resistir los embates de la modernidad capitalista: proyectos de infraestructura carretera, presas hidroeléctricas, minería, turismo, urbanización y demás. Estos megaproyectos son planificados y decididos entre las grandes corporaciones y los gobiernos de turno, sin consultar a las comunidades que serán afectadas.

El discurso del desarrollo siempre menciona las bondades de la inversión privada que habrá de generar empleos, crecimiento y prosperidad: son proyectos que cumplen normas ambientales, son socialmente responsables y respetuosos de la comunidad. Por su parte, la gestión del desarrollo procede mediante alianzas público-privadas que descansan en la repartición del territorio a favor de grandes monopolios de origen nacional e internacional, a través de la desposesión de los territorios y una guerra no declarada en contra de los pueblos indígenas a quienes se tiene por improductivos: una traba del desarrollo.

A fin de analizar este problema se sigue la clave conceptual de la acumulación por desposesión de Harvey (2004), en concreto se revisa el caso del Istmo de Tehuantepec por dos razones: es un espacio estratégico para los inversionistas privados debido a su ubicación estratégica y por alojar la mayor diversidad biológica del país; a la vez es el sitio donde habitan pueblos indígenas con una profunda raíz material, cultural, con el territorio y están dispuestos a defenderlo. 
Es central en el libro el concepto de diversidad biocultural porque permite entender la formación de las comunidades en un contexto socioambiental que ha sido tasado como capital natural, un reservorio de recursos naturales que puede ser apropiado por las grandes corporaciones. Si por una parte se señala que en esas regiones los pueblos indígenas preservan lenguas, normas, formas de gobierno así como modos de producción que conviven con una gran variedad de especies animales y vegetales, y que en tal sentido contribuyen al mantenimiento y conservación de los ecosistemas; también se advierte que en las entrañas de la tierra existen yacimientos minerales, petrolíferos y gasíferos, además hay suficiente agua.

El desarrollismo neoliberal extractivo abre espacios al capital mediante la diversificación de los megaproyectos según una lógica geopolítica expansiva de corte neocolonial, la cual introduce nuevas formas de despojo de los bienes comunales que en los territorios indígenas se traduce como la práctica destrucción de la diversidad biológica y cultural, los modos de vida. Como saldo histórico se ahonda una deuda social y ecológica que trasgrede los derechos humanos y gesta una gran crisis socioambiental.

La geografía del extractivismo es el nuevo mapa del México profundo, un mapa barroco donde se superponen las concesiones ilegítimas (aunque legales), las zonas devastadas, las violencias estructurales y criminales, la proliferación de conflictos y movimientos de resistencia. Estos mecanismos de dominación económico-política pretenden disolver, una vez más, a los pueblos indígenas y campesinos («campesindios», diría Bartra, 2008) mediante la violencia, expropiación, represión, cooptación, chantaje. No obstante, también se verifican procesos de resistencia de comunidades que se niegan a ceder sus territorios: desde la década de 1990 tiene lugar en México, y en América Latina, una emergencia de los movimientos indígenas, los cuales están reescribiendo la historia y marcando la pauta de los procesos de transformación social aún en ciernes. 
En la región andina se protagonizaron episodios como la «guerra del agua», una integración de movimientos sociales indígenas-sindicales-populares en frentes electorales triunfantes que formaron gobiernos bajo ideas movilizadoras extraídas de la cosmogonía indígena, como el vivir bien, que se tradujo en la reelaboración de la carta constitucional, la formación de un Estado plurinacional que incluye nuevas instancias de poder popular, la extracción de rentas mineras, petroleras y gasíferas para las políticas sociales de los gobiernos progresistas. Procesos que ahora están en cuestión, pero donde interesa resaltar el protagonismo indígena.

La noción de bienestar indígena posee distintas denominaciones. En el libro se alude a la comunalidad de Oaxaca y se explora cómo el pensamiento y la práctica indígena han sido articulados por las organizaciones y liderazgos comunitarios y reforzados por intelectuales indígenas. Para nutrir los procesos de resistencia se exploran ideas movilizadoras, que a la par del vivir bien (Acosta, 2010) y la comunalidad (Esteva, 2015) puedan orientar la defensa de la diversidad biocultural, la dotación de derechos y el bienestar de los pueblos indígenas y campesinos. No existe un desarrollo alternativo enmarcado en la modernización, en el neoliberalismo, sino alternativas al desarrollo que se construyen en la práctica social comunitaria, desde abajo, y no por prescripciones de política pública o de recetas de los organismos internacionales, como es la pauta dominante; esto puede hacerse extensivo a otros ámbitos de comunidad.

$\mathrm{Al}$ principio y al final del texto se pronuncia una idea: resistir, resistir al desarrollo. Aunque también se vislumbra que en México y en el resto de América Latina quienes más tenazmente han resistido son los pueblos indígenas, no porque sean más osados, y lo son, sino porque defienden su territorialidad, su cultura. Quizá otras formas de resistencia sean de igual modo ejemplares, hasta más emblemáticas dentro de la modernidad capitalista, pero son más volátiles y episódicas, así se trate de la defensa de un salario, una elección, un presupuesto. 
Luchas importantes, pero mediadas siempre por el capital y el Estado, por tanto, sus alcances siempre están enmarcados en los límites impuestos por el poder del gran dinero. En cambio, la lucha por el territorio tiene otra lógica, se efectúa desde, o al menos eso se pretende, la autonomía y la autodeterminación, no para contribuir a las dinámicas de acumulación, para reclamar un lugar privilegiado o modesto dentro del sistema, sino para preservar la cultura material de los pueblos en el México profundo, sin que esto quiera decir que se vivirá ajeno a los designios de los mercados globales; cabe la posibilidad de ciertas desconexiones estratégicas, pero son formas de lucha o resistencia que sólo pueden emerger desde un ámbito comunitario, articulado, vivencial, en los márgenes, periferias o intersticios del sistema. De ahí que las defensas, las luchas y las utopías puedan retomar algunas enseñanzas de la cosmovisión indígena: la autonomía y la autodeterminación, la organización desde el sentido propio. Los ámbitos de comunidad y nuevas formas de hacer política pueden ser detonadores de las luchas por otras formas de organizar la economía donde no se privilegie el interés de las rentas de los territorios y de la diversidad biocultural sino los intereses de la vida digna, en el sentido analizado por Carlos Lucio.

Dos grandes procesos han sido lesivos para las clases subalternas (indígenas, campesinos, obreros; pequeños industriales y comerciantes; mujeres; jóvenes; pero en primer lugar los pueblos indígenas). Por una parte, los procesos de formación del Estado nación (amparado en el mito de la Colonia como proceso civilizatorio, el mito del mestizaje como homogeneización sociocultural, el mito de la revolución como ideología nacionalista, el mito de la democracia como la disolución de clases en ciudadanía electiva) que descansan en el fetichismo del poder del presidencialismo renovado por el neoliberalismo y la integración de un nuevo bloque social de poder (tecnoburocracia y nuevos ricos magnates rentistas, tipo Carlos Slim) que reproducen y amplifican los mecanismos 
de dominación ancestrales y contemporáneos: el colonialismo interno, el despojo y la violencia. Por otra parte, los procesos de formación del capital periférico (economías de enclave de tipo extractivismo y maquilador, la economía criminal).

En contravención a tales procesos formativos, que en conjunto hacen posible una simbiosis modernizadora, aparece la formación o preservación de los ámbitos de comunidad, primero como intento de preservar la identidad, cultura y organización de los pueblos indígenas y campesinos ante las amenazas del despojo, la explotación y la violencia, para luego ascender a un protagonismo mayor con la formación político-cultural de clase (Otero, 2004), donde el ámbito de comunidad es recreado desde la autonomía frente al Estado y la independencia ante los partidos políticos. Una forma de orientar estos procesos es el ámbito de lo común, que no es estatal (no se trata de depositar en el Estado y su tecnoburocracia la dirección de la vida social ni de amplificar la propiedad pública como espacio de una comunidad nacional imaginaria y armónica) y tampoco es un ámbito privado (donde los intereses exclusivos y egoístas orientados por el mito de la mano invisible logren cristalizar un bien común y donde sea necesario sólo vigilar, regular y castigar a los infractores de las normas del mercado); sino que es un ámbito donde se gestan instituciones comunitarias bajo normas y procedimientos decididos por cuenta propia en aras de un bienestar o un vivir bien, una cogestión del espacio común donde los bienes no son privados ni estatales, son bienes comunales. 


\section{Referencias}

Acosta, A. (2010). «El buen vivir, una utopía por (re)construir». Casa de las Américas (257).

Bartra, A. (2008). «Campesindios. Aproximaciones a los campesinos de un continente colonizado». Boletín de Antropología Americana (44).

Bonfil Batalla, G. (1990). México profundo. Una civilización negada. México: Grijalbo/ Conaculta.

Esteva, G. (2015). «Para sentipensar la comunalidad». Bajo el volcán 15(23).

González Casanova, P. (1963). «Sociedad plural, colonialismo interno y desarrollo». América Latina. Revista del Centro Latinoamericano de Ciencias Sociales 6(3).

Lucio, C. (2016). Conflictos socioambientales, derechos bumanos y movimiento indígena en el Istmo de Tebuantepec. México: Universidad Autónoma de Zacatecas.

Otero, G. (2004). ¿Adiós al campesinado? Democracia y formación política de las clases en el México rural. México: Miguel Ángel Porrúa/ Universidad Autónoma de Zacatecas.

Stavenhagen, R. (1963). «Clases, colonialismo y aculturación. Ensayo sobre un sistema de relaciones interétnicas en Mesoamérica». América Latina. Revista del Centro Latinoamericano de Investigaciones en Ciencias Sociales 6(4). 